\title{
Towards Redundancy in Urban Landscapes: Enhancing Adaptive Capacity Through Design
}

\author{
Rob Roggema ${ }^{1,2}$ \\ ${ }^{1}$ Cittaideale, Office for Adaptive Design and Planning, Wageningen, the Netherlands \\ ${ }^{2}$ Institute for Culture and Society, Western Sydney University, Parramatta, Australia
}

Email address:

rob@cittaideale.eu

\section{To cite this article:}

Rob Roggema. Towards Redundancy in Urban Landscapes: Enhancing Adaptive Capacity Through Design. Urban and Regional Planning. Vol. 6, No. 1, 2021, pp. 15-25. doi: 10.11648/j.urp.20210601.12

Received: December 19, 2020; Accepted: December 31, 2020; Published: January 12, 2021

\begin{abstract}
While many are convinced striving for resilient cities is worth pursuing, the majority of the research in this field focuses on risks and vulnerabilities or on social resilience. The attention for the spatial necessities to create cities that are able to accommodate the impacts of climate change is rare. The core objective of this paper is to learn from resilient urban precedents so design beyond disaster can be practiced. This article focuses therefore on the inclusion of spatial redundancy in urbanism. It uses the example of Western Sydney, where in the future approximately 800,000 new inhabitants will live, to illustrate how certain space can be kept free of developments, in other words remains available for future (changed, unexpected) use. This future use could well be temporary, in the case of climate impacts, such as floods or fires. A total of eight urban neighborhoods have been analyzed as precedents of ecological urbanism and densities. The design principles derived from these precedents are subsequently deconstructed and reconstructed to design the Master Plan and plans at urban design level. Out of this design process, five design principles emerge as determinants of redundancy: use space temporarily so it can be used differently when needed, full integration of the rural and urban landscape (water) systems; developing fluid densities in the city so these can be densified when required in the future; see landscape as an amenity being the space that residents can use when they need; and create accessible communal urban spaces and can be used for shared purposes.
\end{abstract}

Keywords: Redundancy, Urban Design, Climate Adaptation, Resilient Cities, Research by Design, Western Sydney

\section{Introduction}

Cities are currently under stress of occurrences of uncertain and unprecedented events, often induced by unpredictable climate change. Whilst the change in temperature is well known and, within margins, well predicted, the impacts that result from this rise in temperature are more uncertain. Climate events and hazards such as storm surges, cyclones and flash floods that are difficult to predict, impact on cities and landscapes. Also, heat waves, droughts and bushfires are events that are likely to occur, but difficult to predict when, where and how severe they will manifest themselves.

The aim of the research presented in this article is to detect design principles to enhance the adaptive capacity of cities. This is undertaken by investigating existing precedents in sustainable urban plans and neighborhoods and insert these abstracted design principles in the design for future urban projects. The result of this is a set of core design principles which can be used for designing resilient urban environments, hence improving their adaptive capacity.

\section{Literature Review}

Both the Hyogo and Sendai frameworks [1, 2] have emphasized that action is required to reduce the impact of disasters and the disasters themselves. The effect of these frameworks however can be disputed. Between 2005 and 2015 , the period in between both the agreements, 'disasters have continued to exact a heavy toll and, as a result, the well-being and safety of persons, communities and countries as a whole have been affected. Over 700 thousand people have lost their lives, over 1.4 million have been injured and approximately 23 million have been made homeless as a result of disasters. Overall, more than 1.5 billion people have been affected by disasters in various ways, with women, children and people in vulnerable situations disproportionately affected. 
The total economic loss was more than $\$ 1.3$ trillion. In addition, between 2008 and 2012, 144 million people were displaced by disasters. Disasters, many of which are exacerbated by climate change and which are increasing in frequency and intensity, significantly impede progress towards sustainable development. Evidence indicates that exposure of persons and assets in all countries has increased faster than vulnerability has decreased, thus generating new risks and a steady rise in disaster-related losses, with a significant economic, social, health, cultural and environmental impact in the short, medium and long term, especially at the local and community levels. Recurring small-scale disasters and slow-onset disasters particularly affect communities, households and small and medium-sized enterprises, constituting a high percentage of all losses. All countries - especially developing countries, where the mortality and economic losses from disasters are disproportionately higher - are faced with increasing levels of possible hidden costs and challenges in order to meet financial and other obligations' [2].

Therefore, the UNDISR states that 'It is urgent and critical to anticipate, plan for and reduce disaster risk in order to more effectively protect persons, communities and countries, their livelihoods, health, cultural heritage, socioeconomic assets and ecosystems, and thus strengthen their resilience. Enhanced work to reduce exposure and vulnerability, thus preventing the creation of new disaster risks, and accountability for disaster risk creation are needed at all levels. More dedicated action needs to be focused on tackling underlying disaster risk drivers, such as the consequences of poverty and inequality, climate change and variability, unplanned and rapid urbanization, poor land management and compounding factors such as demographic change, weak institutional arrangements, non-risk-informed policies, lack of regulation and incentives for private disaster risk reduction investment, complex supply chains, limited availability of technology, unsustainable uses of natural resources, declining ecosystems, pandemics and epidemics. Moreover, it is necessary to continue strengthening good governance in disaster risk reduction strategies at the national, regional and global levels and improving preparedness and national coordination for disaster response, rehabilitation and reconstruction, and to use post-disaster recovery and reconstruction to "Build Back Better", supported by strengthened modalities of international cooperation. There has to be a broader and a more people-centered preventive approach to disaster risk. Disaster risk reduction practices need to be multi-hazard and multisectoral, inclusive and accessible in order to be efficient and effective. While recognizing their leading, regulatory and coordination role, Governments should engage with relevant stakeholders, including women, children and youth, persons with disabilities, poor people, migrants, indigenous peoples, volunteers, the community of practitioners and older persons in the design and implementation of policies, plans and standards. There is a need for the public and private sectors and civil society organizations, as well as academia and scientific and research institutions, to work more closely together and to create opportunities for collaboration, and for businesses to integrate disaster risk into their management practices' [2].

Reading these carefully negotiated phrases in the Sendai framework, which can also be found in the Hyogo Framework of Action [1], and other UN-supported frameworks have become empty shells. They are full of the right jargon and too political engaged, not societal nor embedded in reality. As such, they are of little use today to understand risk and respond to disasters. But people (even those in poor countries) use them for fear of 'missing the boat'. Should this empty - but sometimes heart lifting jargon be perpetuated or condoned? Instead, these frameworks must be challenged, showing their limitations, blind spots, and overlooks. Only in this way the choice where to invest will be able to reduce in disaster risk (after: [3]).

'The overall conclusion is that both the Hyogo Framework for Action (UN, 2005) and the Sendai Framework [2] fail to deal with root causes of disaster' [4]. The question is: 'Should we not take a critical step back from mottos, oft-repeated phrases, neologisms, and metaphors that may serve as prison bars, walls, and jailors?' [4], in order to '...get beyond frameworks?'.

If we want to concretely get beyond the frameworks' phrasery, the overall objective as formulated in the Sendai Framework needs to be revisited. The objective is to: 'Prevent new and reduce existing disaster risk through the implementation of integrated and inclusive economic, structural, legal, social, health, cultural, educational, environmental, technological, political and institutional measures that prevent and reduce hazard exposure and vulnerability to disaster, increase preparedness for response and recovery, and thus strengthen resilience' [2].

This (nearly) exhaustive summing up of the fields where measures should be undertaken seems to be complete, but quantity is not always similar to completeness. In particular, spatial measures are completely absent, not to mention the role creativity-rich, design-led approaches can play in promoting innovative land-use, at the same time increasing preparedness and engaging the local population and institutions $[5,6]$. Attention to the role spatial measures can play, emphasize the effectiveness to tackle the wickedness of aiming to technically solve disaster risks at the same time convincing the public about the seriousness of the hazards and aligned problems, while never reaching the most vulnerable groups as they have other, more important business to take care of 'eat, sleep, survive'. The creative design-led approaches directly respond in a tangible way to a range of objectives as formulated under priority three in the Sendai framework. They are able:

1) 'To promote coherence across systems, sectors and organizations related to sustainable development and to disaster risk reduction in their policies, plans, programs and processes.

2) To promote the mainstreaming of disaster risk assessments into land-use policy development and implementation, including urban planning, land degradation assessments and informal and non-permanent housing, and the use of guidelines and 
follow-up tools informed by anticipated demographic and environmental changes.

3) To promote the mainstreaming of disaster risk assessment mapping and management into rural development planning and management of, inter alia, mountains, rivers, coastal flood plain areas, drylands, wetlands and all other areas prone to droughts and flooding, including through the identification of areas that are safe for human settlement, and at the same time preserving ecosystem functions that help to reduce risks.

4) To promote cooperation between academic, scientific and research entities and networks and the private sector to develop new products and services to help to reduce disaster risk, in particular those that would assist developing countries and their specific challenges.

5) To strengthen the design and implementation of inclusive policies and social safety-net mechanisms, including through community involvement, integrated with livelihood enhancement programs, and access to basic health-care services, including maternal, newborn and child health, sexual and reproductive health, food security and nutrition, housing and education, towards the eradication of poverty, to find durable solutions in the post-disaster phase and to empower and assist people disproportionately affected by disasters.

6) To strengthen the sustainable use and management of ecosystems and implement integrated environmental and natural resource management approaches that incorporate disaster risk reduction' [2].

The need for transforming our approaches to 'treatment' of disaster risk is therefore evident.

\section{Transformative Thinking}

Several persistent problems related to negotiating frameworks are the cause of not precipitate in areas where the disasters actually occur. As a matter of fact, they do not reduce disaster risk, but merely soften the disruption of or after an actual disaster. We should be talking about PDS (Post-Disaster Softening) instead of DRR (Disaster Risk Reduction). At several points a fundamental transformation of perspective is needed (figure 1) [2].

1) A transformation needs to happen from the ever present (international) consultants in favor of encouraging local initiative.

2) Optimism about new jargon need to be replaced by words with true meaning. Easier said than done, but reliance on frameworks and agreements anticipate bureaucratic language. In itself one cannot disagree with those well-thought words, but for the people living in a vulnerable area they are meaningless. Would street-talk help?

3) Transforming public-private partnerships in people partnerships. The essence being that people need to partner to make it work instead of the potential financial profits guides decisions and collaborations.

4) Moving away from wooly objectives that seem to be acceptable for everyone, but when is put the money where the mouth is. Effectuation of nice words should instantly be translated into means and the way objectives are implemented.

5) Transformation of the technology discourse towards ecological approaches which allow for synergetic thinking rather than singular end solutions to disruptive problems.

6) Instead of talking with, and engaging residents and involving the community, the transformation from this superficial way of participation to an actual influence of local inhabitants to make decisions themselves.

7) Moving from a governance model in which fuzzy policy planning in the form of lengthy texts to spatial design which allows people to visualize how a resilient and disaster free future looks like.

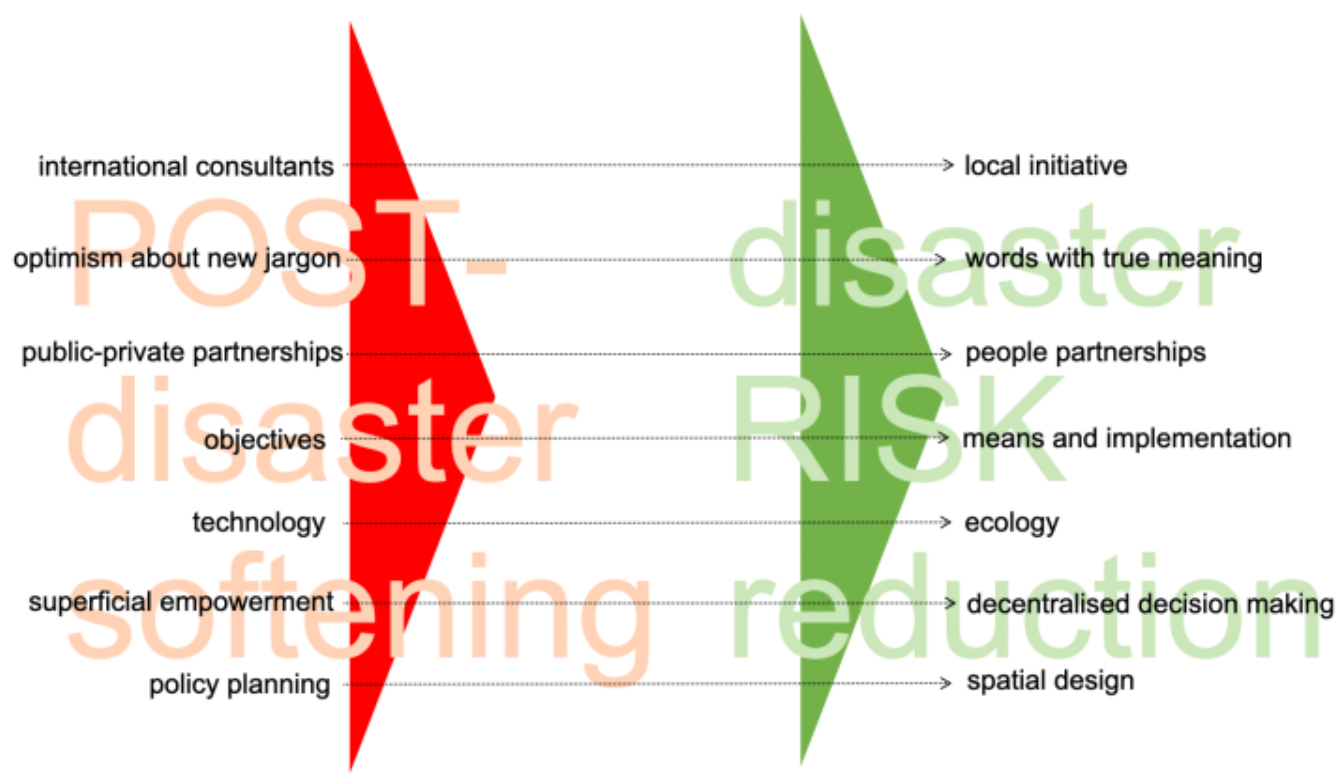

Figure 1. Transformative necessities (after [3]) 


\subsection{Bypassing Disaster}

At first, the way disasters are perceived should be discussed. A disaster is a disruption of the system hence increasing the resilience of the system will help to deal with it. However, there are several ways of increasing the resilience of the system [7]. Systems adaptive capacity hence its resilience can be increased after, be maintained during or created before the disruption occurs (figure 2). The first way is responding to the disruption by rebuilding a better, more resilient system back, also referred to as 'Building Back Better'. The Rebuild by Design process [8] that was set up after hurricane Sandy hit NYC is an example of this approach.

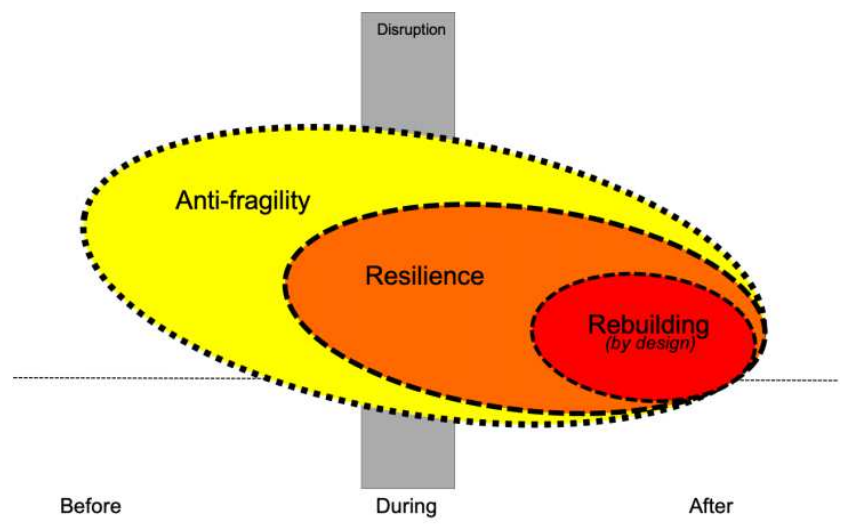

Figure 2. Responding before, during or after a disruption.

In essence, although it creates resilience down the line, the fact resilience is created after the disaster proves it was not a resilient situation after all. It can be questioned whether this is truly in the spirit of how a resilient system should be operating. Resilience is a characteristic not only required by the city and the society after, but preferably during, or in anticipation of, a disruption. Indeed, this implies it should be planned ahead. Planning for and therefore anticipating a future that is potentially disastrous should aim to increase the strength, resilience and quality of life, even becoming anti-fragile [9], using the powers of the disruption to grow stronger and being less fragile.

\subsection{Using the Imaginable}

In the last century, humankind increasingly trusted on engineering approaches to technically solve problems. This is a deterministic approach, which, in essence, makes use of probabilities. The bell-curve (figure 3) divides the full spectrum of events according their chance to occur. The more a certain event is predicted to happens, the more focus lies on these occurrences and more energy will be devoted to find solutions for these problems. In general, this is a sound approach, because when we can solve the majority of problems only few remain a hindrance. This is perfectly fine when 'things are normal', i.e. not disruptive or uncertain. However, when unprecedented events could happen, and due to climate change, chances are increasing these will occur more often, the periphery of the bell-curve are no longer sufficiently covered. After all, these events are rare, so devoting large budgets to deal with these seldom events seem silly. But, as the disasters with the biggest impact always occur at these peripheries of bell-curves, many more people suddenly find themselves back within the vulnerability range. One way of dealing with this problem is to include these events within the design paradigm. By understanding what might happen (the periphery of the bell-curve), we can include these in the design for the future (figure 3) and respond accordingly.

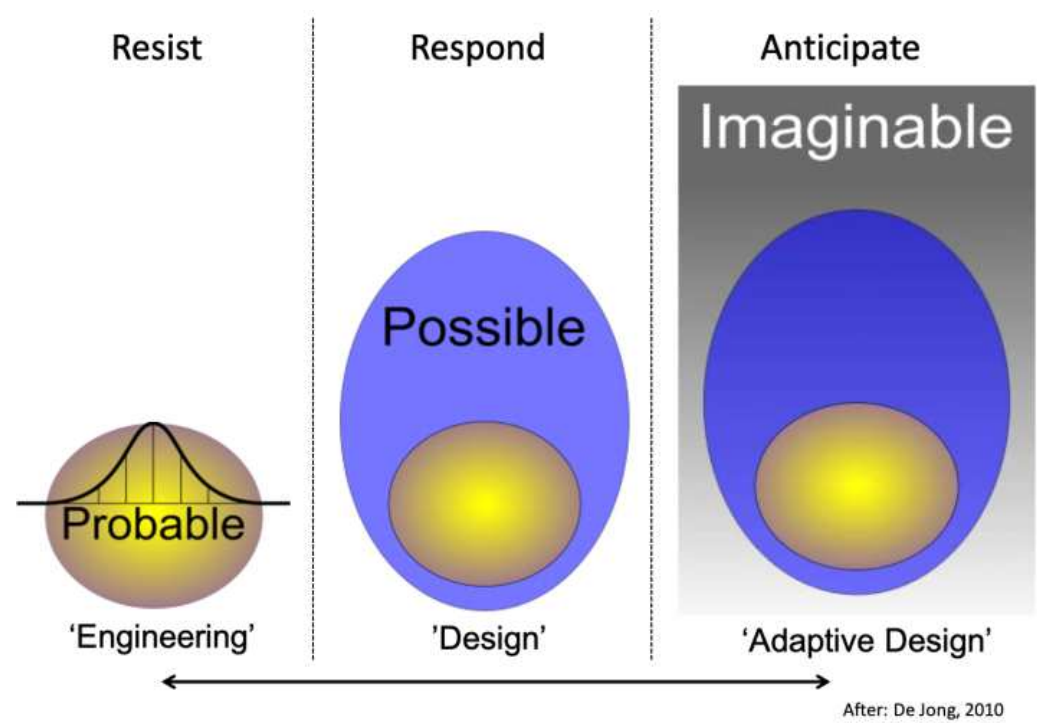

Figure 3. Three approaches to resilience. After: [10].

However, including all possibilities not always suffices, as the events that do not fit in the curve at all are still not taken into account. Unprecedented events, or the unknown unknows, which by their very nature can only be imagined, 
do not fit contemporary paradigms. These events are the most dangerous because these are neither expected nor predicted. In these cases hence in any case, we need to use our imagination to literally imagine what has never happened before. Only this way we can anticipate this unknown and uncertain future. A design approach is able to constantly adjust spatial configurations to a suddenly emerging context, making it possible to accommodate these unknowns. Spatial flexibility and spatial voids [11] are needed to design urban systems that can grow stronger when the unexpected event occurs.

\section{Opportunities Using Spatial Design}

The dynamics in different parts of cities can be very distinctive. Each precinct changes in its own manner. Three fundamental other paces of urban change are distinguished [12]. The first pace that urban design has to cater for is dealing with an urbanization according the growth paradigm. This fast way of developing cities is driven by the market, population growth and a belief in and pursuit of economic prosperity. In this paradigm it is essential to build the number of houses demanded, the amount of industrial zones the market wants, the accompanying road systems and all other uses that are needed to meet the urban demand. Calculating these demands is therefore crucial in the fast urbanism paradigm. (figure 4).

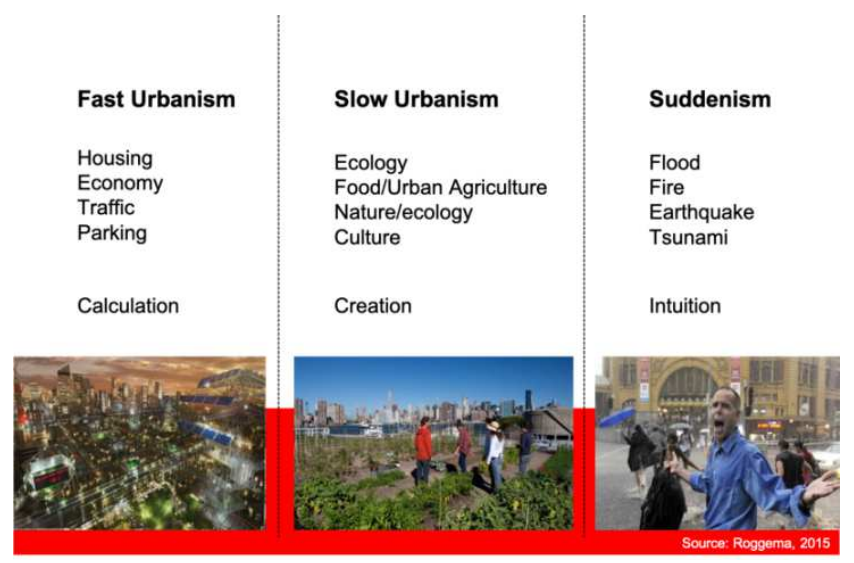

Figure 4. Three paces of urbanism [12].

However, not every urban area, an urban development or certain uses change at a fast pace. A second pace of urbanism accommodates a slow change, so certain functions are given the time to develop, to grow naturally or can be used to contemplate. The elements in the city that benefit from such a slow pace of development are natural and green spaces, urban agriculture and urban water systems. It is essential that these urban functions are not only created at once, but are subsequently taken care of, and nurtured so that their have the freedom to emerge as desired.

A third type of urbanism is when change happens extremely quickly, for instance when spatial phenomena are unprecedented, such as floods, bushfires and earthquakes. Being a surprise to planners, and urban inhabitants these impacts are difficult to plan for. But also, for these sudden urban changes, the city should be designed. Due to the extreme fast pace of change, 'suddenism' requires room for intuition in the design approach.

Every city has to accommodate all paces of change, simultaneously. In the design for the city all of these paces of change need to be accommodated. Spaces need to be allocated for the right amount of growth, other spaces for the slow, care-requiring functions and a third category of spaces must be reserved for events that happen suddenly. The smarter the urban design the more overlap between these spatial categories is arranged and the better the mix of uses in the city becomes.

Accommodating the different development paces and anticipating the unknowns at the same time, the anti-fragility must be given ample opportunities and be stimulated. This can be achieved when urban environments are planned for including flexibility and creating the space so that new developments can be easily incorporated. It is essential the potentials of a place are understood, emphasizing the most sustainable solutions, by including spatial redundancy in the planning. When space is available, serendipity happens, counterintuitive futures come within reach and the different paces of change can be accommodated.

Urban design practice should therefore be transformed, as to the present day, the way urban planning is executed is dominated by well-understood numbers and overly fixed expectations about the future. Luckily, there is a growing awareness of the necessity to respond in advance to emergencies in urban landscapes. In advance, because when cities would only react after a disaster the urban landscape ends up becoming an emergency landscape, planned for the purpose of dealing with disasters only, not for the benefits of the urban environment as such. This outlook on the future is rather sad.

A novel way of anticipating an unknown future is to design voids in the urban environment [11], in a time without acute threats or possible disasters. When an emergency happens, these spaces have the ability to transform and accommodate the use determined by the type of emergency. This implies that spaces in the urban landscape must be suitable for multiple uses. The water square project(s) in Rotterdam [13] clearly illustrate the change of use these urban squares undergo when it starts raining. The square transforms into a water storage, which can be used by children to play. Another good example of increasing redundancy in the landscape is the Floodable Eemsdelta project [14], in the northern part of the Netherlands. In this plan, parts of the landscape are made redundant but are used for agriculture until the impact of sea level rise and/or storm surges make it necessary to change the landscape turning it into a 'water world', as it is flooding where the space anticipates the sudden change to occur.

In this article the possibilities to increase resilience by introducing redundancy in spatial plans is investigated. The core objective of this chapter is to learn from urban design precedents that have proven their resilience through redundancy, and could, when transiting the thinking to 
vulnerable areas could enhance designing beyond disasters. It aims to gain insights in how redundancy in the form of designing unused spaces in urban landscapes could increase the overall resilience. Space is therefore planned to adopt multiple uses hence increase the flexibility and adaptability of the urban landscape. A Research by Design approach is applied to discover the potential for redundancy in the so-called Third City in Western Sydney.

\section{Planning Western Sydney}

For this research the Third City is used as case study area.
In its regional plan for Sydney Metropolitan area the Greater Sydney Commission has proposed to look at the conurbation as a set of three complementary, connected and distinguishable cities. The eastern, First City, is the old harbor city in the east, the second, Central City is the river city around Parramatta, and the Third City is the western city, the newly to be developed city around the new airport of Badgerys Creek in Sydney's western outskirts (figure 5). The Third city will be home to around 800,000 inhabitants in a parkland landscape, which, in summer, is under threat of serious heat waves up to $47^{\circ} \mathrm{C}$ and occasional flash-flooding of up to nine meters.

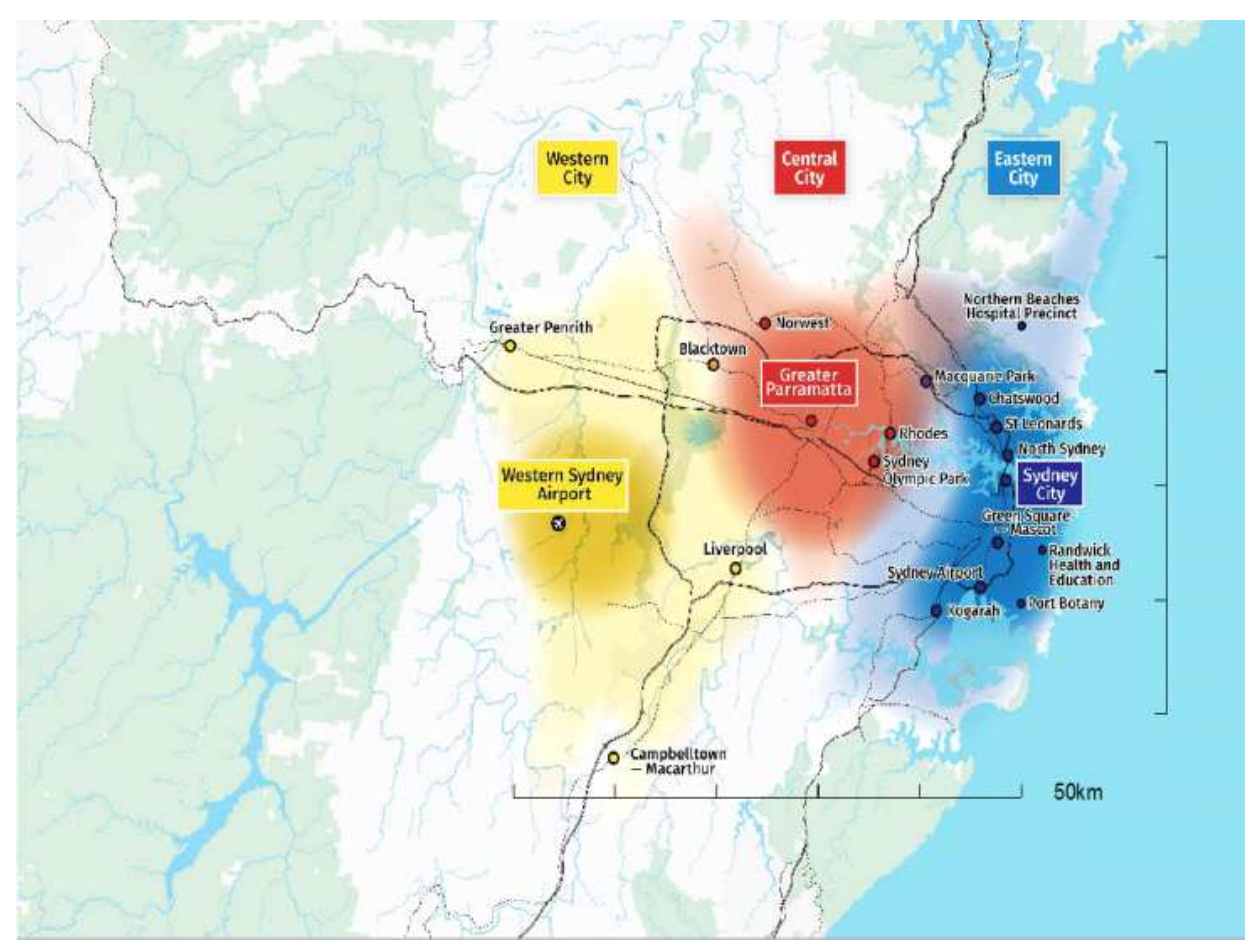

Figure 5. Three cities in Metropolitan Sydney [15].

The way the research is carried out is through Research by Design, which 'generates critical inquiry through design work that may include realized projects, proposals, possible realities or alternatives' [16]. Design studios, as well as professional practice and design-led research projects are seen as methods belonging to Research by Design [17]. In this case, two studios in the Master of Architecture, taught in 2017, Research by Design was used to investigate the spatial potentials to include redundancy in urban designs. In an iterative process, design propositions were developed based on design inquiry of precedents, deriving spatial principles to design with and judge the potential outcomes on a set of criteria.

Two sets of precedents have been investigated, focusing on the eco-cities of HafenCity, in Hamburg [18, 19], Hammarby, in Stockholm [20, 21], Haverleij, in the Dutch city of Den Bosch [22] and Borneo-Sporenburg, in Amsterdam [23, 24] and additionally using four of the densest cities in the world (Cairo, Paris, Madrid and Marrakesh). For each of these precedents design principles were deconstructed and then again reconstructed in the new context of the Third City (figure 6). Based on the criteria, these new propositions could be judged whether they contributed to future resiliency in the design propositions for the Third City. The criteria used in the design process were twofold:

1) Would the design include temporary use of space hence increase spatial redundancy?

2) Could environmental flows of water, energy, materials and food be closed at a local scale?

During the design process the design principles were continuously tested along these criteria and reiterated in new design propositions. Five core design principles (section 5) emerged from these models of existing urban designs and precincts.

\section{Design Principles}

The precedents of the four ecocities and the four dense urban environments were deconstructed and from each of these analyses design principles were derived $[25,26]$. As an 
example, the design for the ecocity of HafenCity in Hamburg includes double usage of spaces, managing occasional flooding, making it possible to experience the space of the river Elbe suddenly as a public amenity. Additionally, the plan foresees wastewater to be recycled within the neighborhood, condensed pocket parks are part of a refined system of public, private but publicly accessible and private green, of which the majority is car-free, but accessible for service vehicles and public transport. The densities and building blocks in this precinct vary in size, scale and height.

When the dense city of Marrakesh is analyzed, its propositions resemble a sustainable way of dealing with water which is, partly underground, circulated from storage basins to run throughout the dense city. Existing waterways are prepared to mitigate flooding. A green system of high-quality parks forms a green corridor running through the city. The schools, mosques and shops are connected to core public spaces at walking distance, and the housing typologies are designed to adapt to future extensions and new, mixed uses. Self-organization eventually determines which the most demanded best future adjustments are for these redundant spaces.

The outcomes of this investigation into the eight precedents show a strong attention on redundancy, fluidity and sustainability, and these themes have subsequently been used in several design iterations to create designs for the
Third City at different scales.

Detailed design elements have been deconstructed from the urban design precedents and are categorized (figure 6) and linked to the two main criteria, redundancy and circularity. Out of this collection five core design principles could be extracted:

1) Landscape as amenity: available space outside the city that functions as visual or usable space for urban inhabitants.

2) Fluid densities: densities that can be increased (or decreased) over time, in contrast to many current urban design practices which often propose a set of fixed densities, e.g. a plan for an area that fixes specific density categories for each part of the area, not taking into account the three paces of urbanism as described before.

3) Integrated urban-rural water system: integration of all types of water in the urban landscape, from river water to grey household water, groundwater and rainwater, all to be part of one water system.

4) Redundant space; spaces that are not determined yet for a certain use or are consciously used temporarily, and current land-use will be sacrificed when the space is needed for a sudden change.

5) Accessibility and communal urban spaces: space that is open to the public, even if in private ownership, and can be used for shared purposes, such as urban farming.

\section{De-Constructed in Precedents}



\section{Re-Constructed in Designs}

Resilient City - Michaed Zappis Make use of the potential of the landscape and green Riparian zones, creeks and floodzone as large scale spatial amenity Fluid edge of floctzone and urban area; the urban is permeable for temporary Weconnecting and extending ecological remnants Grey water recycling system courses and helophytes
City patterns and built form is made adaptableadjustable


Adaptable and variety of block sizes and scas Small geen parks part of high dersity blocks Shades spaces with trees Keep open spaces to create responsive urban fabric
ofic Fludity between parkland and built-up area in $2 \mathrm{D}$ and $3 \mathrm{D}$; the landscape continues under built spaces
Rehabilitation of natural environment in and outside urtan area amenity, parkland and reuselrecycling of Adaptive to flood patterns, can change over time Transition of water and wind patterns for cooling building and ownerstip RidgCity - Julia Young Highest densites on ridges; outside these space is redundant veatinent, water cooling, wettand remediation Water collected in man-made ponds
Closed grey water recycling localised close to homes Redundart space for highest biodiversity Highest densities at the edge of the urtan area: create windtunnels and shade Landscape and creeks for recreation and activites
Priority for bikes and charging electric bikes Renevable energy generation in redundart space (bio-energy), solar and Goortma nurbar

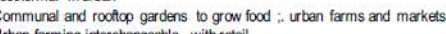

Gully City - Holly Julian Wind diretor walking and cycling (Obesity) Wettand rion guided into neightborhood (cooling) Riparian land kept freelredundart for future growth of food Ridges not developed and kept redundant for future renewable energy generation Increase of amenity (landscape)

Figure 6. Deconstructed precedents linked via design principles with reconstructed designs. [25, 26].

Four design projects [27-30] have subsequently been used to reconstruct the design principles into designs for the Third
City (figure 6). Two of these design projects are illuminated in this article. 


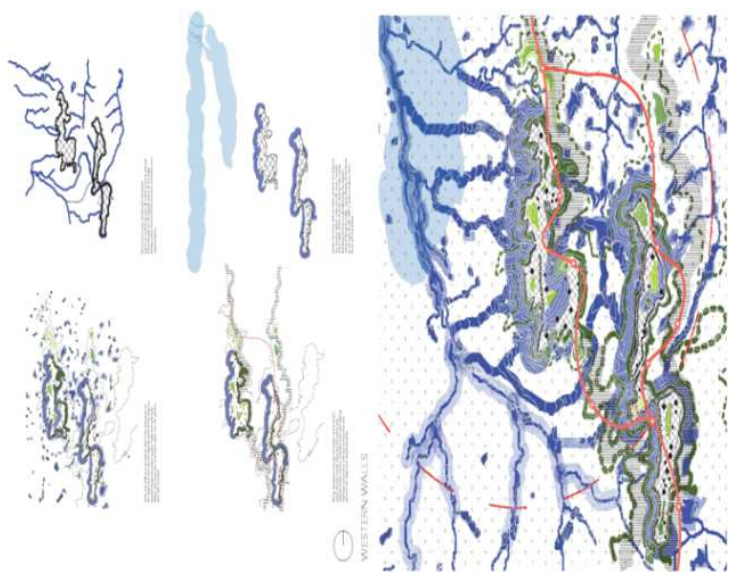

Figure 7. RidgCity [29].

\subsection{RidgCity}

At Master Plan level RidgCity [29] (figure 7) proposes to concentrate the highest densities on the ridges in the landscape to create redundant space outside this elevated landscape, which is then usable as water treatment, water which is able to cool the city and wetland remediation. Additionally, the redundant space is used for emerging nature hence improves biodiversity, for recreation and leisure activities, and generating renewable energy via bio-crops. In the high-density urban environments, grey water is recycled, rainwater is collected in man-made ponds, priority is given to bikes and pedestrians, and local natural sources (solar, geothermal) supply locally generated renewable energy. The highest residential buildings are positioned in a way they provide shade and construct a wind tunnel effect for cooling. Communal urban farming is integrated on roofs, through food markets and urban farms, even in redundant retail spaces.

By increasing the density in compact precincts on ridges above the 100-meters contour the rest of the landscape is a redundant space for accommodating climate impacts, such as floods or fires. The precincts are prepared for future heat through their compactness, the presence of water and by enhancing wind-flows. In this design exploration, environmental flows of water, energy and food are fully closed.
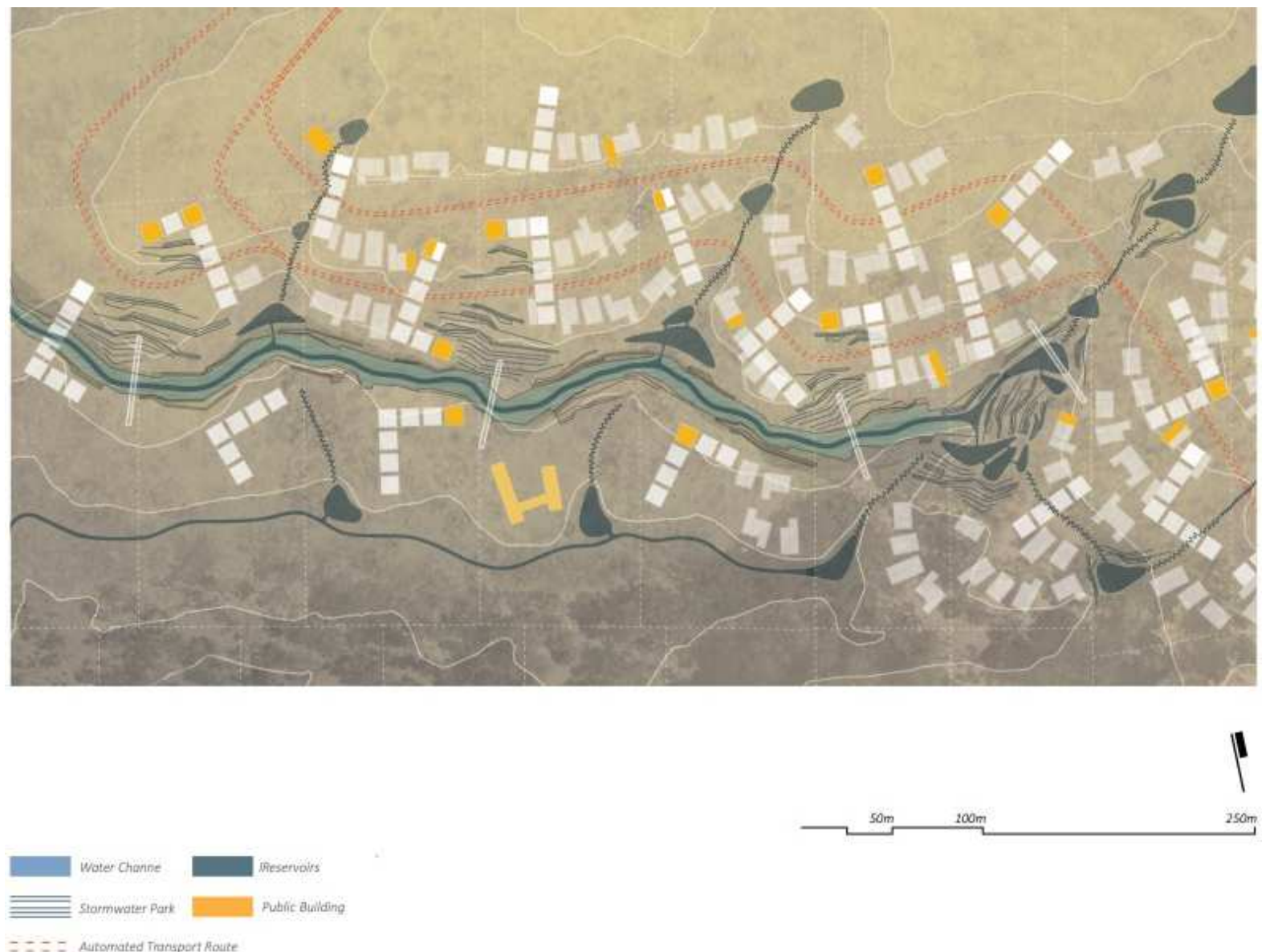

Figure 8. Hydraulic City [28].

\subsection{Hydraulic City}

On a more detailed spatial scale the 'Hydraulic City' [28] introduces redundant spaces not only outside the urban contour, where the natural environment is given the room to regenerate, but it also increases the fluidity within and under the built-up area. The plan takes the water system as the core structuring element. It stores water higher on the hills in reservoirs, after which the water is slowly released to the gully-system, where cleaned household water is added to the 
water system. Afterwards, the water flows are collected and will ultimately flow into the main creek. The landscape forms the basis for creating a responsive urban fabric because redundant space can be adjusted to any future emergency or climate impact. The urban landscape is adaptive to future flood events, but functions also as a resource for inhabitants in the form of a recreative parkland and is able to reuse or recycle waste. The urban form is designed so it can accommodate future demographic and work/life balance changes. Redundant spaces in the building and its direct vicinity can be used for individual or collective extensions of residences.

In the Hydraulic City spaces are kept free for future needs, so flooding, heat or droughts can be mitigated in the landscape and the urban design (figure 8). Moreover, the water cycle is fully integrated with the urban and rural landscape through capturing and storing rainwater. It is designed to recycle and supply grey household water to the rural water system hence increasing the capacity of creeks and streams in the landscape to deal with future floods.

The analysis and the two design examples illustrate how spatial redundancy is used to create the flexibility in the plans so they can be readjusted to any future use whenever it is needed. For instance, this way space is available in the landscape for a flood, even if this flood is more severe than according to the current 1:100-year contours can be expected. Under normal circumstances, without climate hazards, the urban landscape will use these redundant spaces for parkland, nature, or recreation. Only when it is needed these spaces will transform into flood zones, cooling areas, or to mitigate the impacts of bushfires.

The extensive way the urban and rural are integrated and designed, as being one system, helps to balance out the resources used to generate energy from renewable resources, it uses cleaned urban water to supply the rural drought-sensitive water system, and it opens up the possibility to grow food within the urban environment, such as on roofs, inside buildings, even in landscape underneath the city.

Additionally, the designs show that, even in high density areas there is room to extend buildings, should a future densification of the city be desirable. The redundant spaces make it possible to add built structures, rooms, apartments, even elevated townhouses on top of the natural stream.

\subsection{Landscape-based Urbanism}

The design principles of redundancy and circularity have subsequently been used to design a large scale, entirely new, city in Western Sydney for approximately 800,000 future inhabitants. This landscape-based urbanism unites future necessities of climate impacts with current needs for urban living in a sensitive parkland area. It is using the urban and rural water system as the main driver for urbanization patterns, determining the size and locations of densities and urban centers. It also links ecological systems, renewable energy sources and urban food supply in the urban landscape (figure 9).



\section{Conclusion}

If the landscape is taken as the starting point for urbanism, the spaces that are most suitable to be qualified redundant hence are left free of fixed use to take up a range of future changes, can be determined and are useable, on their turn, to design the systems and structures of the future city. These redundant spaces will generate a new normal. Being in use for temporary functions, these spaces can suddenly be transformed into a completely new landscape whenever a climate disaster or climatic impact has to be accommodated. This requires intelligent design of urban spaces, densities and areas that are kept open for future infill. These spaces for temporary use can be located in the landscape but can also present themselves as part of the built form of the city.

In this article the focus lies on creating redundancy in the urban design, which looks mainly at ecology, water and food systems, but less so at mobility. Mobility is a factor that determines the urban appearance heavily, as inhabitants experience their direct urban environment as participants in traffic, public transport and as users of active transport. Especially in a new city of nearly one million people, the mobility solutions are very important, but remain undiscussed in this article. This however does not imply these aspects should be left out of design. It is suggested here these aspects will only be dealt with after the landscape has determined the shape of the city, the redundant spaces and the major areas for residential living. The public transport options, such as heavy rail, and metro and light rail systems become an integral part of these designs in a second stage. Then it is time to prioritize the routes for pedestrians and 
cyclists in the infrastructures proposed as preferential, before discouraging car-use by giving it a low priority in the parking system applied and the accessibility of road systems.

In practice it is not always, or hardly ever the case that sustainable solutions such as closing environmental cycles, or consciously keeping spaces un(der)used for future adaptability of urban environments is leading. Factors, such as landownership and politics, as well as perceived demands of the population, often play a more dominant role in decision-making. These 'economics of the development process' more often determine the final outcome of urban developments. Despite many complain about the delivered spatial results in the form of unsustainable and uninteresting towns and precincts, crucial decisions are not easily made in favor of future needs, because a space without a concrete use is often deemed too uncertain. In conclusion, this requires a major change in mindset of decision makers, planners and citizens alike. However, to prevent disasters from impacting livelihoods and lives of humans and non-humans it is an even unruly as necessary problem to tackle. The transformation from a current post-disaster softening strategy towards a truly disaster risk reduction should be effectuated, not only by mouth, but certainly in deeds.

\section{References}

[1] UN (2005) Report of the World Conference on Disaster Reduction. Kobe, Hyogo, Japan, 18-22 January 2005. https://www.preventionweb.net/files/17671 finalreportconfere ncel.pdf

[2] UN (2015) Sendai Framework for Disaster Risk Reduction 2015-2030. Geneva: UNISDR https://www.undrr.or/publication/sendai-framework-disaster-ri sk-reduction-2015-2030

[3] Lizarralde, G. (2020) Investing in disaster risk reduction for resilience or investing in disaster risk consultants for visibility? Preliminary introduction to the book 'Investing in Disaster Risk Reduction for Resilience'.

[4] Wisner, B. (2020) Five Years Beyond Sendai-Can We Get Beyond Frameworks? Int J Disaster Risk Sci 11 239-249. https://doi.org/10.1007/s13753-020-00263-0

[5] Roggema, R. (Ed.) (2013) The Design Charrette: Ways to Envision Sustainable Futures. Dordrecht, Heidelberg, London: Springer, $335 \mathrm{pp}$.

[6] Uehara, M. Roggema, R. and Fuiji, M. (2020) Effectiveness of sublational discussion-based swarm planning process in the 2011 Japan disaster area: Creating new planning directions combining polarized opinions. International Journal of GEOMATE 19(76) 98-106 (Dec 2020) ISSN: 2186-2982 (P), 2186-2990 (O), Japan, DOI:

https://doi.org/10.21660/2020.74.9151

[7] Gunderson, L. H. and Holling, C. S. (Eds) (2002) Panarchy: Understanding Transformations in Systems of Humans and Nature, Island Press, Washington, DC.

[8] Bisker, J., Chester, A. and Eisenberg, T. (2015), "Rebuild by design", New York, NY, available at: www. rebuildbydesign.org/data/files/500.pdf (accessed 27 July 2019).
[9] Taleb, N. N. (2012), Antifragile: Things That Gain from Disorder, Random House, New York, NY.

[10] De Jong, T. M. (2010), "The role of art in science", METU Journal of Faculty of Architecture, Vol. 27 No. 1, pp. 23-44, available at: http://dx.doi.org/10.4305/METU.JFA.2010.1.2

[11] Roggema, R. (2018) Design with voids; How inverted urbanism increases urban resilience. Architectural Science Review 61 5: 349-357. DOI: 10.1080/00038628.2018.1502153

[12] Roggema, R. (2015), "Three urbanisms in one city: accommodating the paces of change", Journal of Environmental Protection, Vol. 6 No. 9, pp. 946-956, available at: $\quad$ www.scirp.org/journal/jep; http://dx.doi.org/10.4236/jep.2015.69084

[13] Boer, F. (2014). De URBANISTEN, Water-square Benthemplein. A+U Architecture and Urbanism 529. 14:10 Recent Projects. 20-27.

[14] Roggema, R. (ed.) (2012). Swarming Landscapes: The Art of Designing for Climate Adaptation. Dordrecht, Heidelberg, London: Springer, $260 \mathrm{pp}$.

[15] Greater Sydney Commission (2018) A Metropolis of Three Cities; Greater Sydney Regional Plan. Sydney: State of New South Wales.

[16] EAAE/AEEA Research Charter (undated) Research by design, definition. URL:

http://reseaaerch.wikidot.com/research-by-design. Accessed: 9 July 2018

[17] Roggema, R. (2016) Research by Design: Proposition for a Methodological Approach. Urban Science 12 doi:10.3390/urbansci1010002

[18] Grossman, D. (2015) A Tale of Two Northern European Cities: Meeting the Challenges of Sea Level Rise. Yale Environment 360, 3 November $2015 . \quad$ URL: http://e360.yale.edu/features/a_tale_of_two_northern_europea $\mathrm{n}$ cities meeting the challenges of sea level rise. Accessed: $2 \overline{6}$ February 2018.

[19] Serre, D., B. Barroca, M. Balsells and V. Becue (2018), Contributing to urban resilience to floods with neighbourhood design: the case of Am Sandtorkai/Dalmannkai in Hamburg. Journal of Flood Risk Management 11 (1) S69-S83. doi:10.1111/jfr3.12253

[20] Iverot, S. P., A. Vernay, K. F. Mulder and N. Brandt (2013) Implications of systems integration at the urban level: The case of Hammarby Sjöstad, Stockholm. Journal of Cleaner $\begin{array}{llll}\text { Production } & 48 & 220-231 . & \text { DOI: }\end{array}$ 10.1016/j.jclepro.2012.09.012

[21] Brogren, M. and A. Green (2003) Hammarby Sjöstad-an interdisciplinary case study of the integration of photovoltaics in a new ecologically sustainable residential area in Stockholm. Solar Energy Materials \& Solar Cells 75 761765 .

[22] Van Veldhuizen, D. and Meier, S. (2014) Modern castles and country houses: the use of history in 'gated communities' in The Netherlands. International Journal of Heritage Studies 20 (7-8) 813-833. DOI: 10.1080/13527258.2013.860391

[23] Borret, K. (2001) Amsterdam, Borneo e Sporenburg. Abitare (Milano) 402 48-49. http://hdl.handle.net/1854/LU-143259. 
[24] Yoshida, N. (2002) West-8 Master-Plan of Borneo/Sporenburg, Amsterdam, The Netherlands 1993-1997. A+U-Architecture and Urbanism

[25] Roggema, R. and C. Allchin (2017) GO WEST! Masters Design Studio, School of Architecture, UTS. Autumn 2017.

[26] Roggema, R. and R. Simpson (2017) GO SOUTHWEST! Masters Design Studio, School of Architecture, UTS. Spring 2017.

[27] Julian, H. (2017) Gully City. Sydney: Masters Design Studio GO WEST! Lead by Roggema and Allchin, School of Architecture, UTS, Autumn 2017
[28] Veringa, G. (2017) Hydraulic City. Sydney: Masters Design Studio GO SOUTHWEST! Lead by Roggema and Simpson, School of Architecture, UTS, Spring, 2017.

[29] Young, J. (2017) RidgCity. Sydney: Masters Design Studio GO WEST! Lead by Roggema and Allchin, School of Architecture, UTS, Autumn 2017

[30] Zappia, M. (2017) Resilient City. Sydney: Masters Design Studio GO SOUTHWEST! Lead by Roggema and Simpson, School of Architecture, UTS, Spring, 2017.

[31] Roggema, R. (2017) Design for the third city, Western Sydney. Badgerys Urbanism; winter elective. School of Architecture, UTS. 